\title{
Study on mesoporous catalysts for oxidation of volatile organic compounds
}

\author{
Xianqiang Ran* \\ College of Environmental Science and Engineering, Tongji University, 200092, NO. 1239 Siping \\ Road, Shanghai, China
}

\begin{abstract}
Volatile organic compounds (VOCs) emitted from many industrial processes, are harmful to human health and the atmsphere. Several technologies are currently used to eliminate VOCs from the environment. Among them, catalytic oxidation has been recognized as one of the most efficient and promising ways to treatment VOCs. So high performance oxidants play an dominant role in the catalytic oxidation process. In this work, we discussed many researchers' works about preparation and effect of their catalysts, kinds of mesoporous catalysts for eliminating VOCs were reviewed, the active components of the catalysts are noble and non-noble metal oxides, which loaded in the mesochannels of mesoporous materials including silica, titania and aluminia.
\end{abstract}

\section{Introduction}

Volatile organic compounds (VOCs) are important precursors for the formation of secondary pollutants such as fine particles $\left(\mathrm{PM}_{2.5}\right)$ and ozone $\left(\mathrm{O}_{3}\right)$, which lead to atmospheric environmental problems such as haze and photochemical smog ([1]). VOCs also seriously threatens human health (such as lung cancer, laryngeal cancer and cardiovascular disease ([2-4]). So far, the frequently used technologies to treat VOCs mainly include adsorption ([5]), thermal incineration ([6]) and catalytic oxidation([7]). Compared with adsorption technology using mesoporous materials to eliminate VOCs, there is a much extensive investigation of catalytic oxidation. The catalysts often contain active components and supporter, their activity relies on surface area, pore structure, rich valance, dispersion and reducibility. So the catalysts design is a crucial role to cooperate the supporter and active constituents. In this review, we summarized the mesoporous silica, titania and alumina as supporters and the $\mathrm{MnO}_{\mathrm{x}}, \mathrm{Co}_{3} \mathrm{O}_{4}$ and $\mathrm{CeO}_{\mathrm{x}}$ as active components. The correlation between surface area, pore structure, metal dispersion and catalytic performance of mesoporous materials is discussed.

\footnotetext{
*Corresponding author: henson313@126.com
} 


\section{Recent advances in the active components loaded in the mesoporous oxidants}

Recently, there is an extended growth of attention for the catalysts containing transition metal and rare earth metal oxide nanoparticles (such as $\mathrm{MnO}_{\mathrm{x}}, \mathrm{Co}_{3} \mathrm{O}_{4}, \mathrm{CuO}, \mathrm{Cr}_{2} \mathrm{O}_{3}, \mathrm{CeO}_{2}$ and so on) with mesoporous structure mainly owing to their ideal catalytic activity as well as their cost-effectiveness, as compared with those supported with noble-metals ([8]). It has been widely noted that the preparation route, size of active components, surface area, reaction temperature, channel connectivity may all affect the performance of VOCs catalytic oxidation $([9-11])$.

\section{1 $\mathrm{MnO}_{\mathrm{x}}$ surpported catalysts}

Mesoporous manganese oxides, which present polyvalent, novel chemical and physical properties, have been investigated widely in the elimination of VOCs. It is reported that the contact condition between $\mathrm{MnO}_{\mathrm{x}}$ and targeted VOCs could strikingly affect the catalytic performance of $\mathrm{MnO}_{\mathrm{x}}$ for VOCs combustion, and the supremely active $\mathrm{MnO}_{\mathrm{x}}$ catalysts are those that display superior oxygen mobility and redox ability ([12-14]). Wu et al. ([15]) fabricated mesoporous $\alpha-\mathrm{MnO}_{2}$ nanorods by means of hydrothermal and template-free approach, which exhibited superior catalytic oxidation performance towards o-xylene $\left(100 \%\right.$ of o-xylene was eliminated at $\left.210{ }^{\circ} \mathrm{C}\right)$. The enhanced catalytic ability was beneficial from its mesoporous structure and enlarged surface area. Tang et al. ([16]) obtained a set of mesoporous $\mathrm{MnO}_{\mathrm{x}}$ by a novel oxalate route without any template, which not only has a well-ordered mesoporous structure and high surface area, but could be synthesized in large quantities. The as-prepared $\mathrm{MnO}_{\mathrm{x}}$ demonstrated exceeding catalytic efficiencies for complete oxidation of benzene, toluene, and o-xylene compared with those synthesized by other various strategies including $\mathrm{NaOH}, \mathrm{NH}_{4} \mathrm{HCO}_{3}$ route, or nanocasting method. Especially, the temperature for benzene conversion of $90 \%\left(\mathrm{~T}_{90}\right)$ was $209{ }^{\circ} \mathrm{C}$, which is $132{ }^{\circ} \mathrm{C}$ lower than the compulsory temperature for the $\mathrm{MnO}_{\mathrm{x}}$ synthesized by the $\mathrm{NaOH}$ route. The ratio of $\mathrm{Mn}^{4+} / \mathrm{Mn}^{2+}$ on the $\mathrm{MnO}_{\mathrm{x}}$ is the key cause to improve the performance of benzene oxidation. Besides, it can be seen that the optimal $\mathrm{MnO}_{\mathrm{x}}$ was remarkably durable in long-term reaction and good water vapor tolerance. Piumetti et al. ([14]) prepared mesoporous $\mathrm{Mn}_{2} \mathrm{O}_{3}, \mathrm{Mn}_{3} \mathrm{O}_{4}$, and $\mathrm{Mn}_{\mathrm{x}} \mathrm{O}_{\mathrm{y}}$ via the solution combustion method and used for complete oxidation of ethylene, propylene, toluene, and their mixture. The obtained $\mathrm{Mn}_{3} \mathrm{O}_{4}$ catalyst, which exhibited the most abundant electrophilic oxygen on the surface, achieved the optimized VOCs conversion. Furthermore, this catalyst revealed increased Brønsted acidic sites owing to various structural defects and of the corresponding Lewis acidic sites, indicating the acidic features play a significant role in the activation of hydrocarbons and occurring intermediates. What' $\mathrm{s}$ more, the $\mathrm{Mn}_{3} \mathrm{O}_{4}$-based monolith $\left(\mathrm{Mn}_{3} \mathrm{O}_{4}\right.$ powder catalyst was deposited on a cordierite-type monolith) not only achieved superior activity towards the total VOCs conversion, but presented excellent durability over a time-on-stream of $10 \mathrm{~h}$ at $310{ }^{\circ} \mathrm{C}$ without apparent deactivation. Mo et al. ([17]) reported Mn-based oxides with oxygen vacancy defects $\left(\mathrm{MnO}_{\mathrm{x}}-\mathrm{ET}\right)$, which advertised the excellent catalytic performance for toluene oxidation $\left(\mathrm{T}_{90}=225{ }^{\circ} \mathrm{C}\right)$ mainly due to the abundant surficial oxygen vacancy and favorable oxygen storage capacity. The results of in situ DRIFTS and XPS were further confirmed that adsorbed oxygen species are identified as active oxygen, as well as increasing $\mathrm{Mn}^{4+}$ concentration boost the considerable efficiency for toluene oxidation. 


\section{$2.2 \mathrm{Co}_{3} \mathrm{O}_{4}$ modified catalysts}

$\mathrm{Co}_{3} \mathrm{O}_{4}$, consist of one tetrahedrally coordinated $\mathrm{Co}^{2+}$ site and two octahedrally coordinated $\mathrm{Co}^{3+}$ sites, has been extensively explored as a potential candidate for VOCs catalytic oxidation ([18]). Li et al. ([19]) prepared a set of mesoporous $\mathrm{Co}_{3} \mathrm{O}_{4}-\mathrm{n}$ catalysts under hydroxycarbonate precipitation route followed the treatment of diluted $\mathrm{HNO}_{3}$ solution and evaluated for toluene oxidation. $\mathrm{Co}_{3} \mathrm{O}_{4}-0.01$, the optimal catalyst, absolutely removed toluene to at $230{ }^{\circ} \mathrm{C}$ and exhibited excellent durability without water vapor. The enhanced catalytic activity can be ascribed to the magnified specific surface area, increased amounts of weak acidic sites, and further abundant surficial $\mathrm{Co}^{2+}$ and adsorbed oxygen species originated from acid treatment, announcing acid treatment could be a promising route to obtained mesoporous $\mathrm{Co}_{3} \mathrm{O}_{4}$ with excellent physicochemical properties and admirable catalytic ability. Zhang et al. ([20]) synthesized $\mathrm{MCo}_{2} \mathrm{O}_{4}(\mathrm{M}=\mathrm{Cu}, \mathrm{Ni}, \mathrm{Co})$ hollow mesoporous spheres (HMS) via solvothermal alcoholysis approach for total oxidation of acetone. In detail, $\mathrm{CuCo}_{2} \mathrm{O}_{4} \mathrm{HMS}$ catalyst presented the best efficiency towards total oxidation of acetone, and $\mathrm{NiCo}_{2} \mathrm{O}_{4}$ also showed a preferred performance compared with $\mathrm{CoCO}_{2} \mathrm{O}_{4}$. There is some evidence that cation-substituting effect may affect the amounts of surficial $\mathrm{Co}^{3+}$ concentration, defective sites, active oxygen species as well as redox ability, and finally play a decisive role in determining the catalytic performance. Additionally, the optimal catalyst displayed attractive long-term stability and was resistant to water vapor.

\section{$2.3 \mathrm{CeO}_{x}$ loaded catalysts}

Recently, mesoporous $\mathrm{CeO}_{2}$ and $\mathrm{CeO}_{2}$-containing materials have been frequently adopted as a major active ingredient or catalytic promotor for VOCs catalytic oxidation owing to their non-poisonous, outstanding oxygen mobility, and unique oxygen storage capacity ([21]). $\mathrm{Li}$ et al. ([22]) fabricated mesoporous $\mathrm{Mn}$-doped $\mathrm{CeO}_{2}$ microspheres with the 3D hierarchical structure on the way of hydrothermal access. They demonstrated that the proportion of $\mathrm{Mn}$ species in $\mathrm{Mn}-\mathrm{Ce}-\mathrm{O}$ composites is vital for their catalytic activity because a moderate amount of $\mathrm{Mn}$ species effectively facilitates to remove chlorine species on the $\mathrm{CeO}_{2}$ active sites, and the composites synthesized by hydrothermal access show an increasing catalytic performance towards oxidation of trichloroethylene compared with those obtained via co-precipitation or sol-gel route. CeMn(0.21)-HT-N6A4, the optimal composite for degradation of trichloroethylene, is beneficial from its large surface area, superior oxygen mobility, and enriched surficial active oxygen species. Zhou et al. ([23]) synthesized ordered mesoporous bimetallic $\mathrm{CeCu}$ oxide catalysts templated from KIT-6 and used for phenyl VOCs catalytic combustion. The molar ratio of $\mathrm{Ce} / \mathrm{Cu}$ is a key factor to determine the ordered degree of mesoporous structure, surficial physicochemical properties, and reducibility of as-prepared catalysts, which plays a dominant role in the catalytic process. Toluene catalytic combustion conversion on the optimized catalyst (CeCu-HT3) at $240{ }^{\circ} \mathrm{C}$ outpaces $99.3 \%$ with diminished toluene concentration to within $70 \mathrm{ppm}$, and the catalytic combustion performance of phenyl VOCs on the CeCu-HT3 obeyed the order ethylbenzene $>$ toluene $>$ xylene $>$ benzene. Yang et al. ([24]) illustrated a serious of mesoporous $\mathrm{CeO}_{2}$-transition metal (including $\mathrm{V}, \mathrm{Cr}, \mathrm{Mn}, \mathrm{Fe}, \mathrm{Co}, \mathrm{Ni}, \mathrm{Cu}$ ) hybrid oxides via coprecipitation approach and applied for deep catalytic oxidation of chlorinated VOCs. The as-prepared hybrid catalysts presented a well mesoporous structure, extensive surface area, and sufficient pore volume, which facilitates the adsorption and activation of VOCs molecules on the internal surface. Interestingly, $\mathrm{Ce}-\mathrm{Cr}$ mixed catalyst showed the highest activity and selectivity for the removal of 1,2-dichloroethane, which mainly owing to the forceful oxidizing activity of formatted $\mathrm{Cr}^{6+}$ species. Besides, the strong interaction 
between $\mathrm{CeO}_{2}$ and $\mathrm{CrO}_{x}$ could avoid coke deposition as well as enhance the resistance to Cl-poisoning because of its desirable redox property.

\section{Recent advances in the supporters of the mesoporous oxidants}

When it comes to the matrix of supported catalysts, the hydrophobic property, pore characteristic, and activity may affect the performance for VOCs catalytic oxidation. Mesoporous materials (such as $\mathrm{SiO}_{2}, \mathrm{TiO}_{2}$, and $\mathrm{Al}_{2} \mathrm{O}_{3}$ ) have been investigated as ideal host supports to carry active components including noble metals, transition metal oxides, and a mixture of them.

\subsection{Oxidants with SBA-15 supporters}

Ordered mesoporous silicas are the most used support for VOCs catalytic oxidation. Rochard et al. ([26]) confined $\mathrm{MnO}_{\mathrm{x}}$ nanoparticles in the mesoporous channels of SBA-15 via the melt infiltration method. The final composites presented an increased catalytic activity towards formaldehyde at low reaction temperature and the $T_{50}$ was dropped to $114{ }^{\circ} \mathrm{C}$ occurred on the optimized one. They suggested that the $\mathrm{Mn}^{3+} / \mathrm{Mn}^{2+}$ redox couple is far less decisive than the $\mathrm{Mn}^{4+} / \mathrm{Mn}^{3+}$ couple in the formaldehyde catalytic oxidation. Tsoncheva et al. ([27]) investigated SBA-15 supported with bimetallic $\mathrm{Cu}-\mathrm{Ce}$ oxides and applied to toluene and ethyl acetate catalytic oxidation. They pointed that the silica matrix could adjust the status of cooperation between the loaded active metal oxide nanoparticles through regulating their diffusion and location into the mesochannels, and the homogenous dispersion of active species leads to boosted catalytic activity in comparison with those non-supported metal oxides.

\subsection{Oxidants with mesoporous $\mathrm{TiO}_{2}$ supporters}

It is reported that $\mathrm{TiO}_{2}$ could enhance the tolerance to chlorine poison, the major cause for the deactivation of the catalytic procedure, of the $\mathrm{TiO}_{2}$-based hybrids ([28]). Mesoporous titania-based supports, therefore, are expected to be a desirable matrix for the removal of chlorinated VOCs. Gao et al. ([29]) investigated bimodal mesoporous $\mathrm{TiO}_{2}$ doped with $\mathrm{Pt}$, $\mathrm{Pd}$, and $\mathrm{Ru}$ through wet impregnation and tested for the catalytic oxidation of dichloromethane. The results indicated that the $\mathrm{Ru} / \mathrm{TiO}_{2}$ was compelling for the elimination of dichloromethane and pretty durable in a long-time catalytic reaction. The enhanced activity may originate from the tendency to decompose carbon and $\mathrm{Cl}$ species, the enlarged pore size would facilitate the desorption of undesirable by-products during the catalytic reaction process. In contrast, the deactivation has easily occurred to $\mathrm{TiO}_{2}$ carried with $\mathrm{Pt}$ or $\mathrm{Pd}$, which may be ascribed to the deposition of carbon species and Cl-poisoning, as well as the generation of $\mathrm{Pt}$ or $\mathrm{Pd}$ species without activity. Barakat et al. ([30]) reported hierarchically macro-mesoporous $\mathrm{TiO}_{2}$ catalysts loaded with noble metals (Au or Pd) and metal oxides $\left(\mathrm{CeO}_{\mathrm{x}}, \mathrm{FeO}_{\mathrm{x}}\right.$, or $\left.\mathrm{NiO}_{\mathrm{x}}\right)$. Among the prepared composite catalysts, $\mathrm{CeO}_{2}$ doped $\mathrm{TiO}_{2}$ with $\mathrm{Pd}$ loaded sample offered the best catalytic activity of toluene, appropriate $\mathrm{CeO}_{2}$ content lead to sufficient surface area values, strong interaction between active species and support, the selectivity for $\mathrm{CO}_{2}$ achieved $100 \%$ after Pd introduced, and therefore lead to better catalytic performance. Yang et al. ([31]) fabricated mesoporous $\mathrm{Nb}_{2} \mathrm{O}_{5}-\mathrm{TiO}_{2}$ composite catalysts through the sol-gel route and applied to adsorption/catalytic oxidation of 1,2-dichloroethane. The $\mathrm{Nb}$ and Ti elements were homogenously dispersed with strong metal-metal interaction and took a better redox/acid activity of the prepared catalysts. They 
illustrated that the mesoporous structure and surficial acidity could effectively promote the activity of the binary $\mathrm{Nb}_{2} \mathrm{O}_{5}-\mathrm{TiO}_{2}$ catalysts to facilitate 1,2-dichloroethane adsorption at low temperatures and consequently an improved catalytic activity compared with pristine $\mathrm{Nb}_{2} \mathrm{O}_{5}$ or $\mathrm{TiO}_{2}$.

\subsection{Oxidants with mesoporous $\mathrm{Al}_{2} \mathrm{O}_{3}$ supporters}

In addition, mesoporous alumina loaded with noble metals, especially $\mathrm{Pb}$ and $\mathrm{Pt}$, has been drawing much attention because of its promising performance towards VOCs catalytic oxidation ([32]). Liu et al. ([33]) obtained mesoporous $\mathrm{Al}_{2} \mathrm{O}_{3}$ doped with Pt-Pd composite through a one-step EISA route and investigated for toluene combustion. The results showed that the $\mathrm{T}_{90}$ and activation energy of the $\mathrm{Pt}-\mathrm{Pd}-\mathrm{Al}_{2} \mathrm{O}_{3}$ is much lower than the one obtained by the conventional wet-impregnation route, which could be mainly attributed to the mean nanoparticle size of noble metals confined in the mesochannels. Chen et al. ([34]) investigated a serious of mesoporous $\gamma-\mathrm{Al}_{2} \mathrm{O}_{3}$ as support for Ce and $\mathrm{Pd}-\mathrm{Pt}$ oxides prepared by a high-temperature solution-phase reduction route. It is found that the $\mathrm{Pd}-\mathrm{Pt}$ oxide nanoparticles were homogeneously dispersed on the surface of the matrix, and the appropriate $\mathrm{Ce}$ content remarkably boosted the adsorption and chemisorption of benzene to active species. The optimal composite, $0.2 \% \mathrm{Pd}-\mathrm{Pt}(1: 1) / 10 \% \mathrm{Ce} / \gamma-\mathrm{Al}_{2} \mathrm{O}_{3}$, showed the best performance for the absolute conversion at $200{ }^{\circ} \mathrm{C}$ with superior maintenance over $1000 \mathrm{~h}$ long-term experiment.

\section{Conclusion}

Catalytic oxidation is the most important method for the removal of VOCs, the excellent performance of mesoporous catalysts were ascribe to their high surface areas, high pore volume for loaded oxygene spieces, ordered and interconnected porous, and the synergic effects of oxides and substrates, supplies enough spaces and proper channels to locate and disperse the mixed-oxide nanoparticles, and also facilitates fast molecular diffusion and transportation for pollutants to contact the active sites in the inner mesopore channels.

\section{References}

1. A. G. Carlton, C. Wiedinmyer, J. H. Kroll, Atmos. Chem. Phys, 9, 4987-5005 (2009)

2. L. F. Liotta, Appl. Catal. B, 100, 403-412 (2010)

3. B. J. Finlayson-Pitts, J. N. Pitts. Science, 276, 1045-1051 (1997)

4. Q. Yang, X. Qiu, R. Li, et al., Chemosphere, 91, 205-211 (2005)

5. M. Franz, H. A. Arafat, N. G. Pinto. Carbon, 38, 1807-1819 (2000)

6. R. Dziembaj, M. Molenda, L. Chmielarz. Catal. Lett, 135, 68-75 (2010)

7. V. Blasin Aubé, J. Belkouch, L. Monceaux. Appl. Catal . B, 43, 175-186 (2003)

8. M.S. Kamal, S.A. Razzak, M.M. Hossain. Atmos. Environ, 140, 117-134 (2016)

9. C. He, P. Li, H. Wang, J. Cheng, X. Zhang, Y. Wang, Z. Hao. J. Hazard. Mater, 181, 996-1003 (2010)

10. B. Solsona, M. Pérez-Cabero, I. Vázquez, A. Dejoz, T. García, J. Álvarez-Rodríguez, J. El-Haskouri, D. Beltrán, P. Amorós. Chem. Eng. J, 187, 391-400 (2012)

11. F. Liu, S. Zuo, C. Wang, J. Li, F. Xiao, C. Qi. Appl. Catal. B: Environ., 148-149, 106$113(2014)$ 
12. J. Deng, L. Zhang, H. Dai, Y. Xia, H. Jiang, H. Zhang, H. He. J. Phys. Chem. C, 114, 2694-2700 (2010)

13. B. Puértolas, A. Smith, I. Vázquez, A. Dejoz, A. Moragues, T. Garcia, B. Solsona. Chem. Eng. J., 229, 547-558 (2013)

14. M. Piumetti, D. Fino, N. Russo. Appl. Catal. B: Environ., 163, 277-287 (2015)

15. Y. Wu, S. Li, Y. Cao, S. Xing, Z. Ma, Y. Gao. Mater. Lett., 97, 1-3 (2013)

16. W. Tang, X. Wu, D. Li, Z. Wang, G. Liu, H. Liu, Y. Chen. J. Mater. Chem. A, 2, 2544-2554 (2014)

17. S. Mo, Q. Zhang, J. Li, Y. Sun, Q. Ren, S. Zou, Q. Zhang, J. Lu, M. Fu, D. Mo, J. Wu, H. Huang, D. Ye. Appl. Catal. B: Environ., 264, 118464 (2020)

18. X. Wang, Y. Liu, T. Zhang, Y. Luo, Z. Lan, K. Zhang, J. Zuo, L. Jiang, R. Wang, ACS Catal., 7, 1626-1636 (2017)

19. G. Li, C. Zhang, Z. Wang, H. Huang, H. Peng, X. Li, Appl. Catal. A: Gen., 550, 67-76 (2018)

20. C. Zhang, J. Wang, S. Yang, H. Liang, Y. Men, J. Colloid. Interf. Sci., 539, 65-75 (2019)

21. M. Mao, H. Lv, Y. Li, Y. Yang, M. Zeng, N. Li, X. Zhao, ACS Catal., 6, 418-427 (2015)

22. H. Li, G. Lu, Q. Dai, Y. Wang, Y. Guo, Y. Guo, Appl. Catal. B: Environ., 102, 475$483(2011)$

23. G. Zhou, H. Lan, T. Gao, H. Xie, Chem. Eng. J., 246, 53-63 (2014)

24. P. Yang, S. Yang, Z. Shi, Z. Meng, R. Zhou, Appl. Catal. B: Environ., 162, 227-235 (2015)

25. G. Rochard, C. Ciotonea, A. Ungureanu, J.M. Giraudon, S. Royer, J.F. Lamonier, ChemCatChem., 121, 664-1675 (2020)

26. T. Tsoncheva, G. Issa, T. Blasco, M. Dimitrov, M. Popova, S. Hernández, D. Kovacheva, G. Atanasova, J.M.L. Nieto, Appl. Catal. A: Gen., 453, 1-12 (2013)

27. M. Kulazynski, J.G. van Ommen, J. Trawczynski, J. Walendziewski, Appl. Catal. B: Environ., 36, 239-247 (2002)

28. S. Cao, X. Fei, Y. Wen, Z. Sun, H. Wang, Z. Wu, Appl. Catal. A: Gen., 550, 20-27 (2018)

29. T. Barakat, V. Idakiev, R. Cousin, G.S. Shao, Z.Y. Yuan, T. Tabakova, S. Siffert, Appl. Catal. B: Environ., 146, 138-146 (2014)

30. P. Yang, J. Li, L. Bao, X. Zhou, X. Zhang, S. Fan, Z. Chen, S. Zuo, C. Qi, Chem. Eng. J., 361, 1400-1410 (2019)

31. H.S. Kim, T.W. Kim, H.L. Koh, S.H. Lee, B.R. Min, Appl. Catal. A: Gen., 280, 125$131(2005)$

32. X. Liu, Q. Zhang, P. Ning, T. Tang, J. Hu, W. Su, Catal. Commun., 115, 26-30 (2018)

33. Z. Chen, J. Li, P. Yang, Z. Cheng, J. Li, S. Zuo, Chem. Eng. J., 356, 255-261 (2019) 